\title{
ANALISIS DAN PERANCANGAN SISTEM INFORMASI AKUNTANSI PENJUALAN, PEMBELIAN, JASA REPARASI MOTOR, DAN PERSEDIAAN BARANG DAGANG PADA PT DAYA ANUGRAH MANDIRI
}

\author{
Sellawati Carbini \\ Yenita Juandy ${ }^{1}$ \\ Sekolah Tinggi Manajemen Informatika dan Komputer LIKMI \\ Jl. Ir. H. Juanda no 96 Bandung \\ yenitajuandy@gmail.com ${ }^{1}$
}

\begin{abstract}
ABSTRAK
Sistem informasi merupakan hal terpenting dalam suatu perusahaan karena dengan adanya sistem informasi maka perusahaan dapat menjalankan usahanya dengan lebih efektif dan efisien dimana pelayanan kepada pelanggan dapat dilakukan lebih cepat, pengolahan data lebih mudah dilakukan, cepat serta dapat meminimalisir kesalahan, penghematan sumber daya manusia, dan penyajian informasi dalam bentuk laporan dapat dilakukan tepat waktu dan akurat sehingga dapat dipergunakan dalam pengambilan keputusan.

Sistem Informasi Akuntansi merupakan bagian dari sistem informasi manajemen yang berfokus pada pengendalian internal untuk melindungi aktiva, data dan informasi yang dimiliki oleh perusahaan. Penulis melakukan analisis yang dituangkan dalam flowmap, merancang sistem baru yang digambarkan dalam Diagram Aliran Data (Data Flow Diagram) dan Diagram Keterhubungan Entitas (Entity Relationship Diagram).
\end{abstract}

Kata kunci : sistem informasi akuntansi, struktur pengendalian internal, pengamanan sistem informasi.

\section{PENDAHULUAN}

Sistem penjualan adalah hal penting bagi pengusaha agar dapat menghasilkan keuntungan untuk mempertahankan kelangsungan hidup perusahaannya. Selain sistem penjualan, sistem pembelian yang baik juga akan menunjang kelancaran sistem penjualan sehingga dapat memenuhi kebutuhan pelanggan. PT Daya Anugrah Mandiri adalah perusahaan yang bergerak dalam bidang penjualan dan pembelian motor, suku cadang serta jasa reparasi motor. Terdapat 2 (dua) pemasok yaitu pemasok suku cadang dan pemasok motor (main dealer).

Pada penelitian ini, penulis menemukan permasalahan dalam perusahaan, diantaranya:

a. Terjadi selisih pada hasil pencatatan di buku dengan stok di gudang.

b. Tidak ada bagian pembelian, sehingga siklus pembelian dilakukan oleh bagian gudang.

c. Pengamanan aktiva lemah.

d. Pembuatan laporan membutuhkan waktu yang cukup lama.

\section{LANDASAN TEORI}

Definisi sistem informasi akuntansi menurut Samiaji Sarosa adalah : "Sistem informasi akuntansi adalah sebuah sistem yang mengumpulkan, mencatat, menyimpan, dan memproses data sehingga menghasilkan informasi yang berguna dalam membuat keputusan." (Sarosa, 2009:12) 
Menurut Azhar Susanto (Susanto, 2013:8) dalam bukunya yang berjudul "Sistem Informasi Akuntansi" menyatakan fungsi sistem informasi akuntansi adalah mendukung aktivitas perusahaan sehari-hari, mendukung proses pengambilan keputusan, membantu pengelolaan perusahaan dalam memenuhi tanggung jawabnya kepada pihak eksternal.

Struktur pengendalian internal menurut Krismiaji, dalam bukunya "Sistem Informasi Akuntansi" adalah sebagai berikut : "Struktur Pengendalian Intern adalah kebijakan dan prosedur yang ditetapkan untuk memberikan jaminan yang layak bahwa tujuan khusus organisasi akan dicapai." (Krismiaji, 2010:219)

Terdapat 5 komponen pengendalian internal, yaitu: pengendalian internal (Control Environment), penilaian resiko (Risk Assesment), aktivitas pengendalian (Control Aktivities), informasi dan komunikasi (Information and Communication), dan pemantauan (Monitoring). Adapun tujuan pengendalian internal adalah untuk menjaga kekayaan organisasi, menjaga keakuratan laporan keuangan perusahaan, menjaga kelancaran operasi perusahaan, menjaga kedisiplianan dipatuhinya kebijakan manajemen.

Menurut V. Wiratna Sujarweni dalam bukunya yang berjudul "Sistem Akuntansi" jenis pengendalian internal yang dilakukan perusahaan berupa pengawasan di antaranya sebagai berikut: (Sujarweni, 2015:76)

a. Menurut tujuannya, terbagi menjadi pengawasan akuntansi dan pengawasan manajemen.

b. Menurut lingkungannya, terbagi menjadi pengawasan umum dan pengawasan aplikasi.

c. Menurut kegiatannya, terbagi menjadi pengawasan preventif, pengawasan detektif, dan pengawasan korektif.

Sistem informasi dalam perusahaan perlu dilindungi dan diawasi dengan cara melakukan pengendalian sistem informasi perusahaan, diantaranya:

a. Pengendalian sistem informasi

Melibatkan prosedur, kebijakan, dan pengendalian untuk menentukan siapa yang dapat mengakses sistem operasi, sumber daya mana yang dapat diakses, dan tindakan apa saja yang dilakukan.

b. Pengendalian manajemen data, terdiri dari 2 kategori, yaitu:

1) Kontrol akses (dirancang untuk mencegah individu yang tidak memilki otorisasi untuk mengambil, merusak, atau menghilangkan data perusahaan).

2) Kontrol pendukung (memastikan bahwa hilangnya data karena akses yang tidak sah, atau bencana fisik, perusahaan dapat memulihkan file database secepatnya).

c. Pengendalian struktur organisasi

d. Pengendalian pengembangan sistem (tindakan yang dilakukan oleh perusahaan untuk mengendalikan aktivitas pengembangan sistem baru)

e. Pengendalian pemeliharaan sistem

f. Keamanan pengendalian pusat komputer

g. Pengendalian internet dan intranet (pengawasan terhadap jaringan)

Ada beberapa macam validasi terhadap field tertentu yang harus diperhatikan, yaitu:

a. Completeness check (pemeriksaan terhadap setiap field terisi dengan lengkap)

b. Field format check (pemeriksaan terhadap format data yang dimasukan)

c. Field length check (pemeriksaan terhadap panjang suatu karakter)

d. Field sign check (emeriksaan yang menentukan tanda sebuah bilangan data berupa angka, berkaitan dengan perhitungan)

e. Limit check (pemeriksan terhadap numeric untuk menentukan telah berada pada range yang benar) 
f. Reasonable check (pemeriksaan kewajaran nilai suatu field lain)

g. Valid code check (pemeriksaan apakah suatu nilai terdaftar pada data yang sah)

Tahap analisis dan perancangan sangat penting karena merupakan tahap awal untuk mendapatkan sistem informasi yang baik. Analisis dan perancangan sistem informasi bermanfaat untuk menerjemahkan kebutuhan pemakai informasi ke dalam suatu rancangan.

Dalam analisis dari perancangan, terdapat beberapa alat bantu yang bermanfaat untuk merancang model sistem yang akan dibangun, yaitu:

a. iagram Arus Data (DAD)

Digunakan untuk mendokumentasikan perangkat logis sistem guna membantu pengguna memahami proses kerja sistem dan untuk memisahkan secara jelas proses logis dan proses fisik perancangan sistem

b. Diagram relasi entitas (Entity Relationship Diagram)

Merupakan suatu model data yang dikembangkan berdasarkan objek.

\section{EVALUASI SISTEM}

Evaluasi sistem bertujuan agar perusahaan mengetahui kekuatan dan kelemahan sistem yang sedang berjalan. Evaluasi sistem pada PT Daya Anugrah Mandiri (Daya Motor) diuraikan [ada Tabel 1.

Tabel 1

Evaluasi Sistem yang Sedang Berjalan

\begin{tabular}{|c|c|c|c|}
\hline \multirow{2}{*}{ No } & \multirow{2}{*}{$\begin{array}{l}\text { Komponen Struktur } \\
\text { Pengendalian Internal }\end{array}$} & \multicolumn{2}{|c|}{ Evaluasi Sistem } \\
\hline & & Evaluasi & Solusi \\
\hline \multirow[t]{5}{*}{1.} & Lingkungan Pengendalian In & nal & \\
\hline & $\begin{array}{l}\text { a. Integritas dan nilai-nilai } \\
\text { etika manajemen }\end{array}$ & $\begin{array}{l}\text { Beberapa karyawan } \\
\text { masih kurang } \\
\text { mematuhi peraturan } \\
\text { jam kerja masuk, dan } \\
\text { tidak ada snaksi }\end{array}$ & $\begin{array}{l}\text { Diberikan sanksi yang } \\
\text { tegas bagi karyawan } \\
\text { yang tidak disiplin. }\end{array}$ \\
\hline & b. Struktur organisasi & $\begin{array}{l}\text { Masih terdapat } \\
\text { beberapa karyawan } \\
\text { melimpahkan } \\
\text { pekerjaan ke divisi } \\
\text { lain. }\end{array}$ & $\begin{array}{l}\text { Harus ada pembagian } \\
\text { tugas dan deskripsi } \\
\text { pekerjaan yang tegas. }\end{array}$ \\
\hline & $\begin{array}{l}\text { c. Filosofi manajemen dan } \\
\text { siklus operasi normalnya }\end{array}$ & $\begin{array}{l}\text { Karyawan suka } \\
\text { terlambat dalam } \\
\text { menyelesaikan } \\
\text { pekerjaan. }\end{array}$ & $\begin{array}{l}\text { Diberikan waktu batas } \\
\text { akhir untuk } \\
\text { menyelesaikan } \\
\text { pekerjaan. }\end{array}$ \\
\hline & $\begin{array}{l}\text { d. Kebijakan dan praktik } \\
\text { perusahaan dalam } \\
\text { mengelola sumber daya } \\
\text { manusianya }\end{array}$ & $\begin{array}{l}\text { Karyawan baru tidak } \\
\text { diberikan pelatihan } \\
\text { khusus. }\end{array}$ & $\begin{array}{l}\text { Perusahaan membuat } \\
\text { program pelatihan } \\
\text { bagi karyawan baru. }\end{array}$ \\
\hline 2. & Penilaian risiko & - & - \\
\hline
\end{tabular}


Sistem Informasi Akuntansi Penjualan, Pembelian, Jasa Reparasi Motor, dan Persediaan Barang Dagang pada PT Daya Anugrah Mandiri

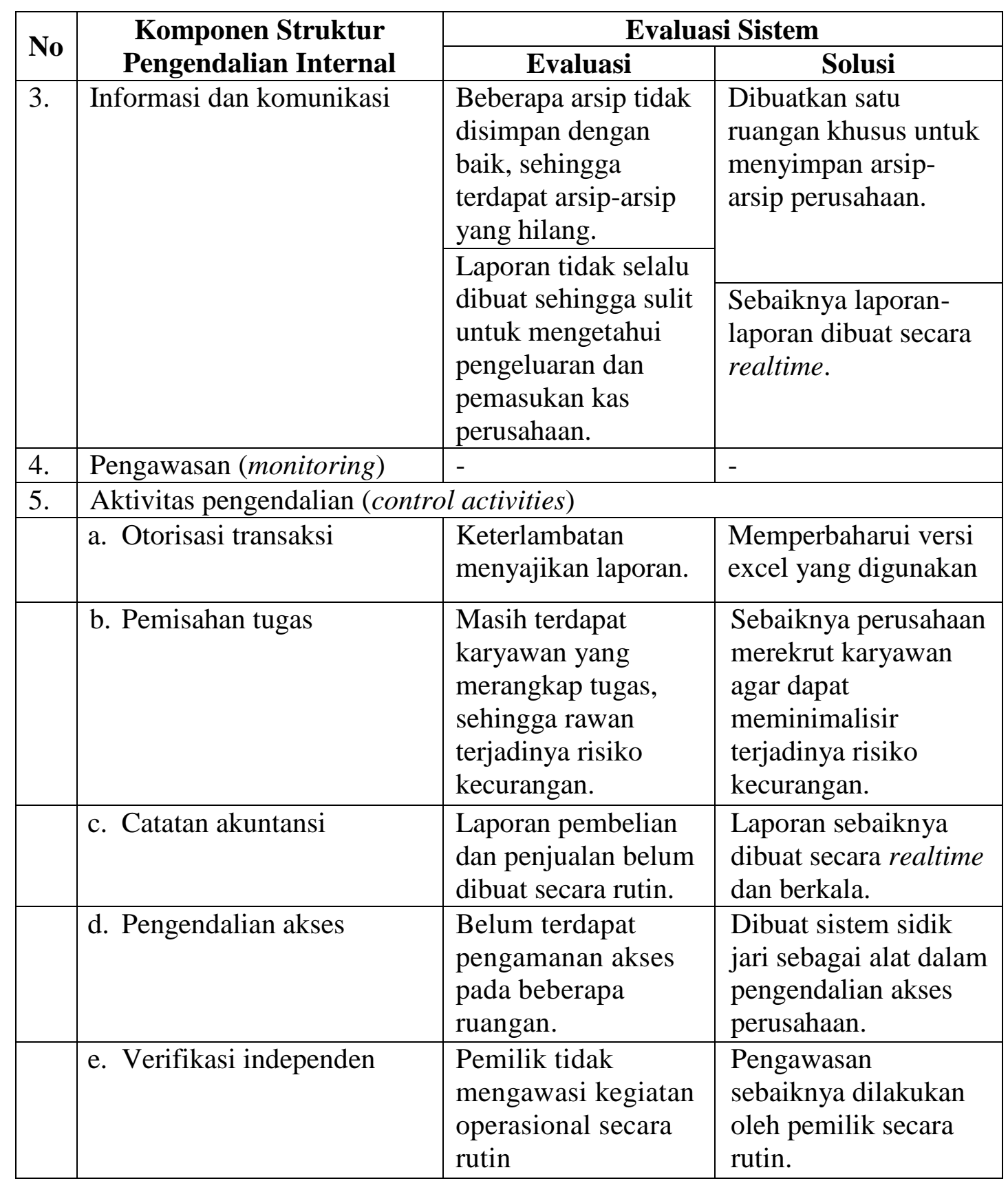




\section{PEMODELAN SISTEM BARU}

Pemodelan fungsional merupakan alat bantu untuk menggambarkan proses-proses yang dibutuhkan oleh sistem perusahaan. Gambar 1 merupakan diagram konteks sistem penjualan, pembelian, jasa reparasi motor, dan persediaan barang dagang.

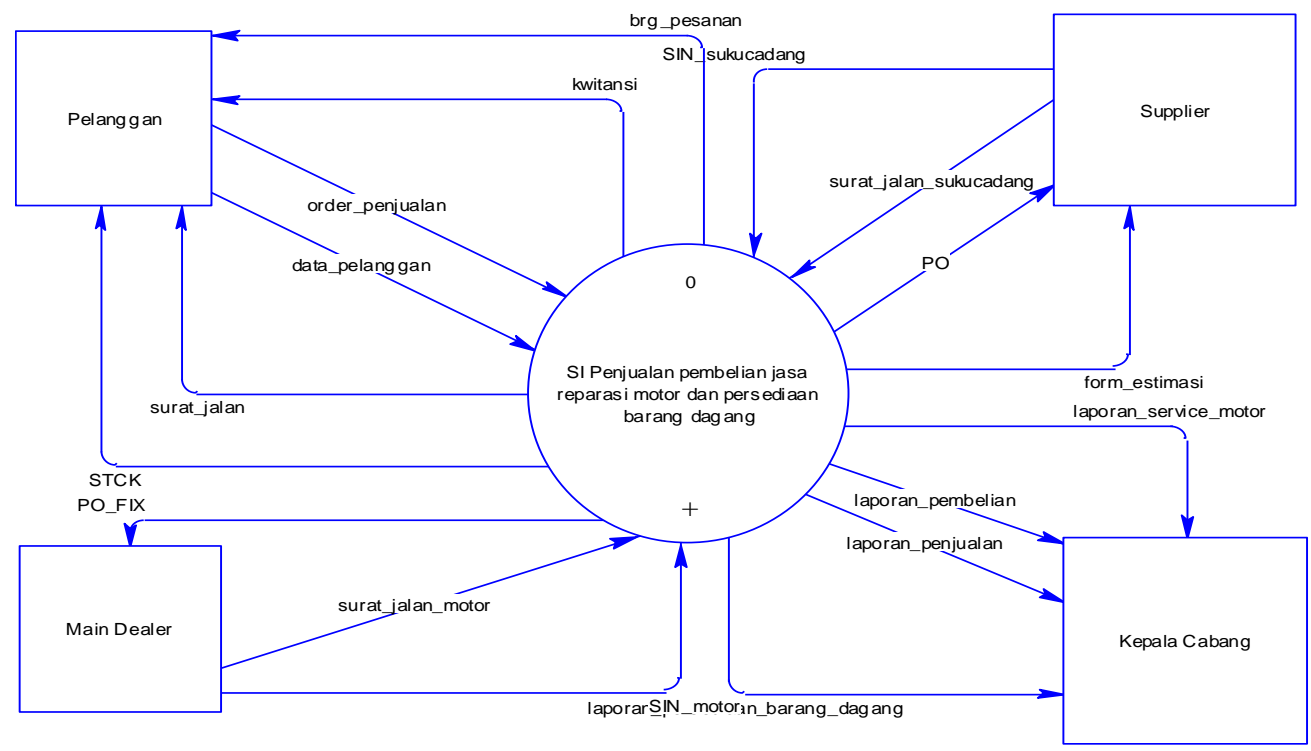

Gambar 1

Diagram Konteks

Diagram relasi entitas Entity Relationship Diagram (ERD) merupakan alat bantu yang digunakan untuk mendesain database. Selanjutnya berdasarkan ERD akan dibuat diagram relasi entitas dan model keterhubungan antar tabel sistem penjualan, pembelian, jasa reparasi motor dan persediaan barang dagang.

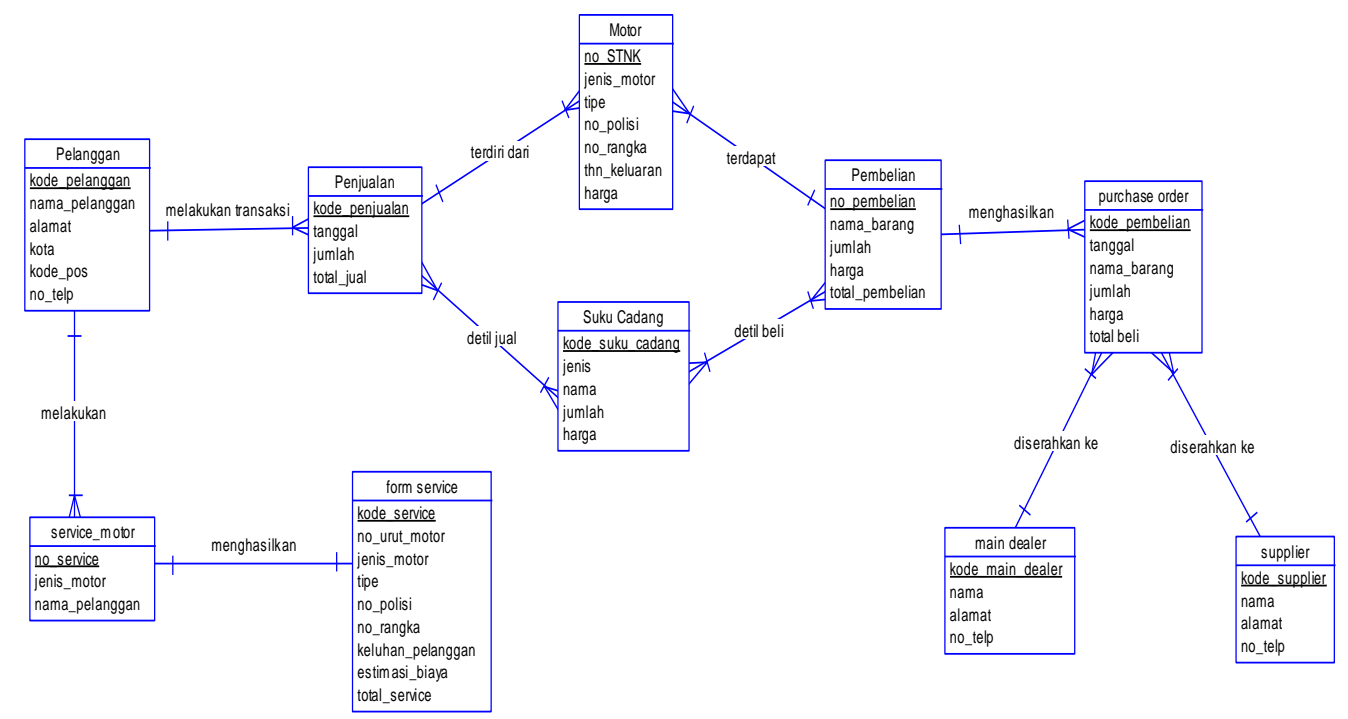

Gambar 2

Entity Relationship Daigram 


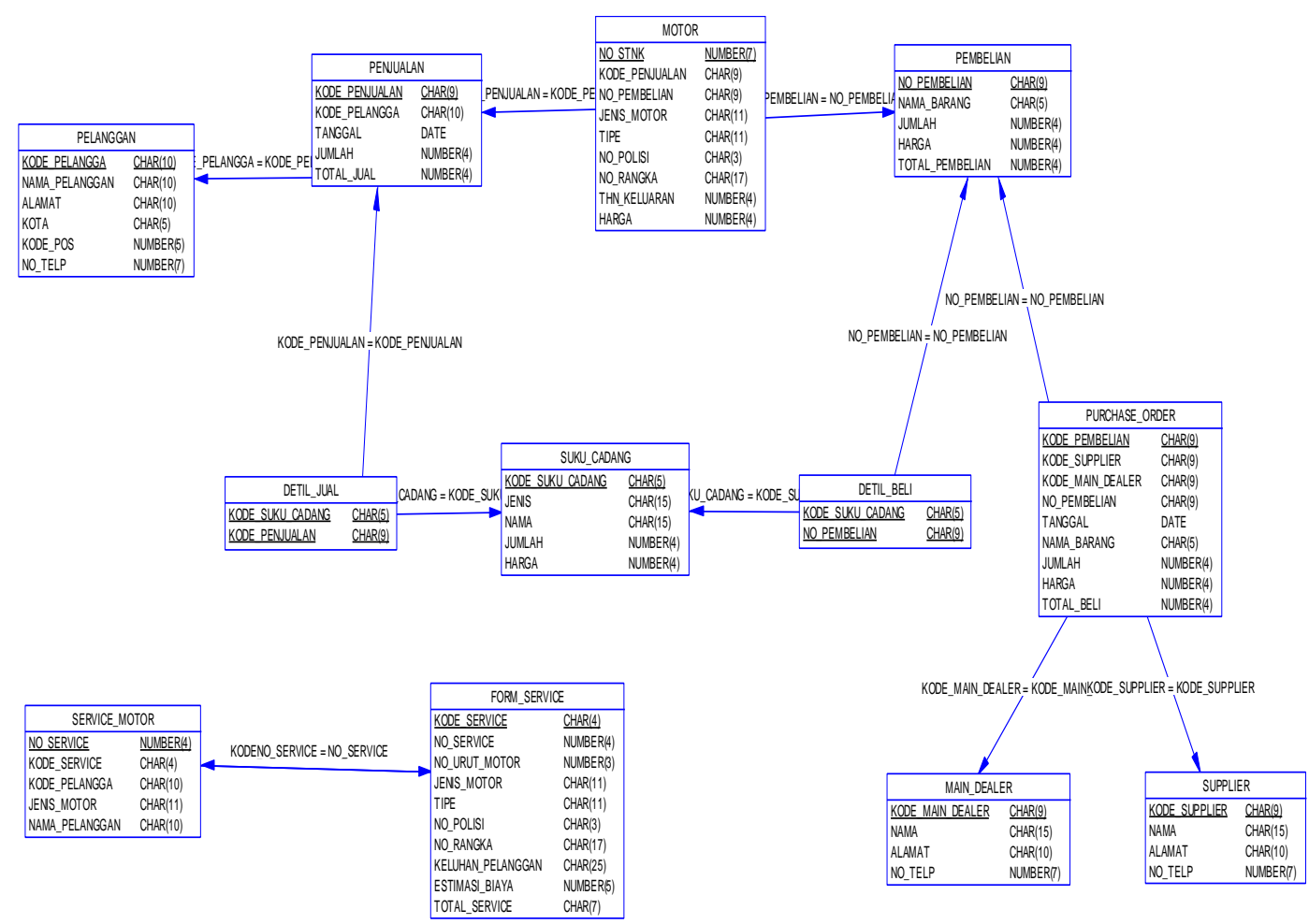

Gambar 3

Model Keterhubungan Antar Tabel

\section{RANCANGAN ANTAR MUKA}

Pada Gambar 4 ditampilkan salah satu contoh perancangan purchase order yang diusulkan penulis. Pada Gambar 5 ditampilkan tata letak layar menu utama aplikasi.

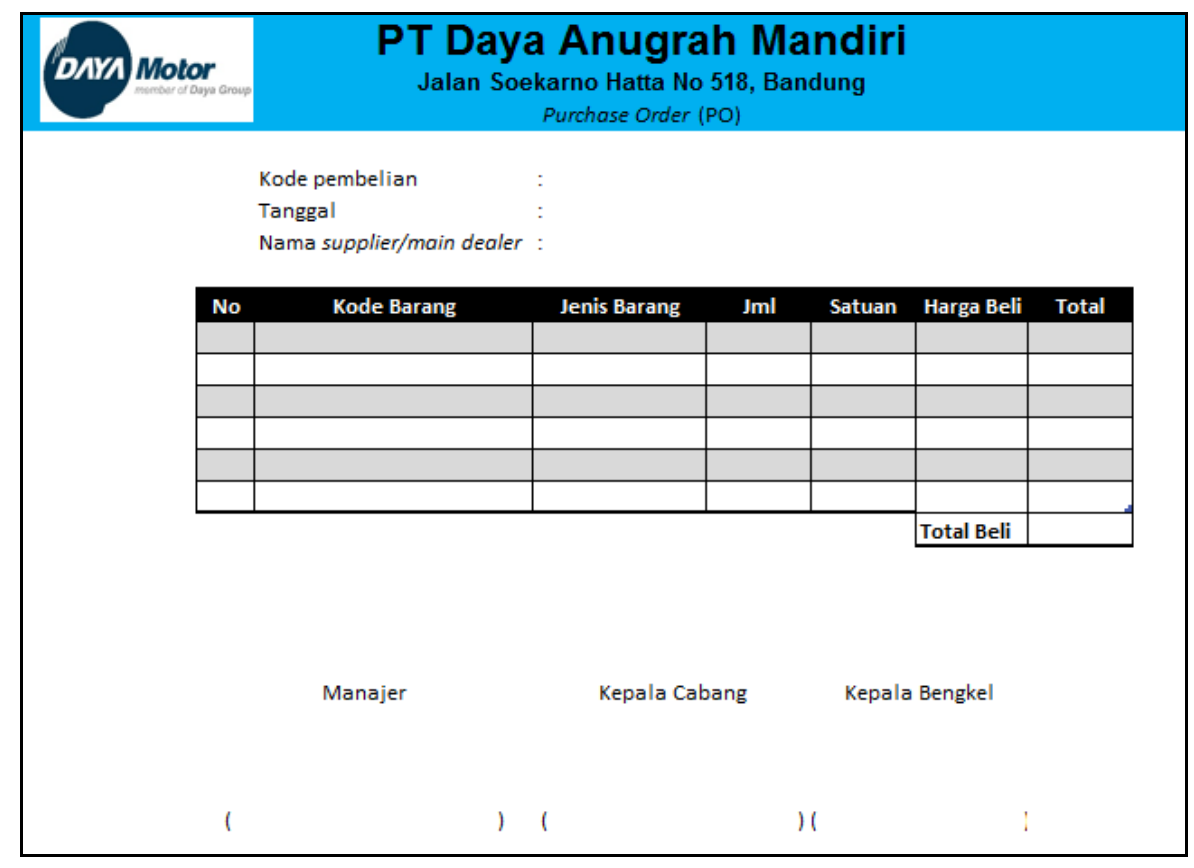

Gambar 4

Desain Purchase Order 


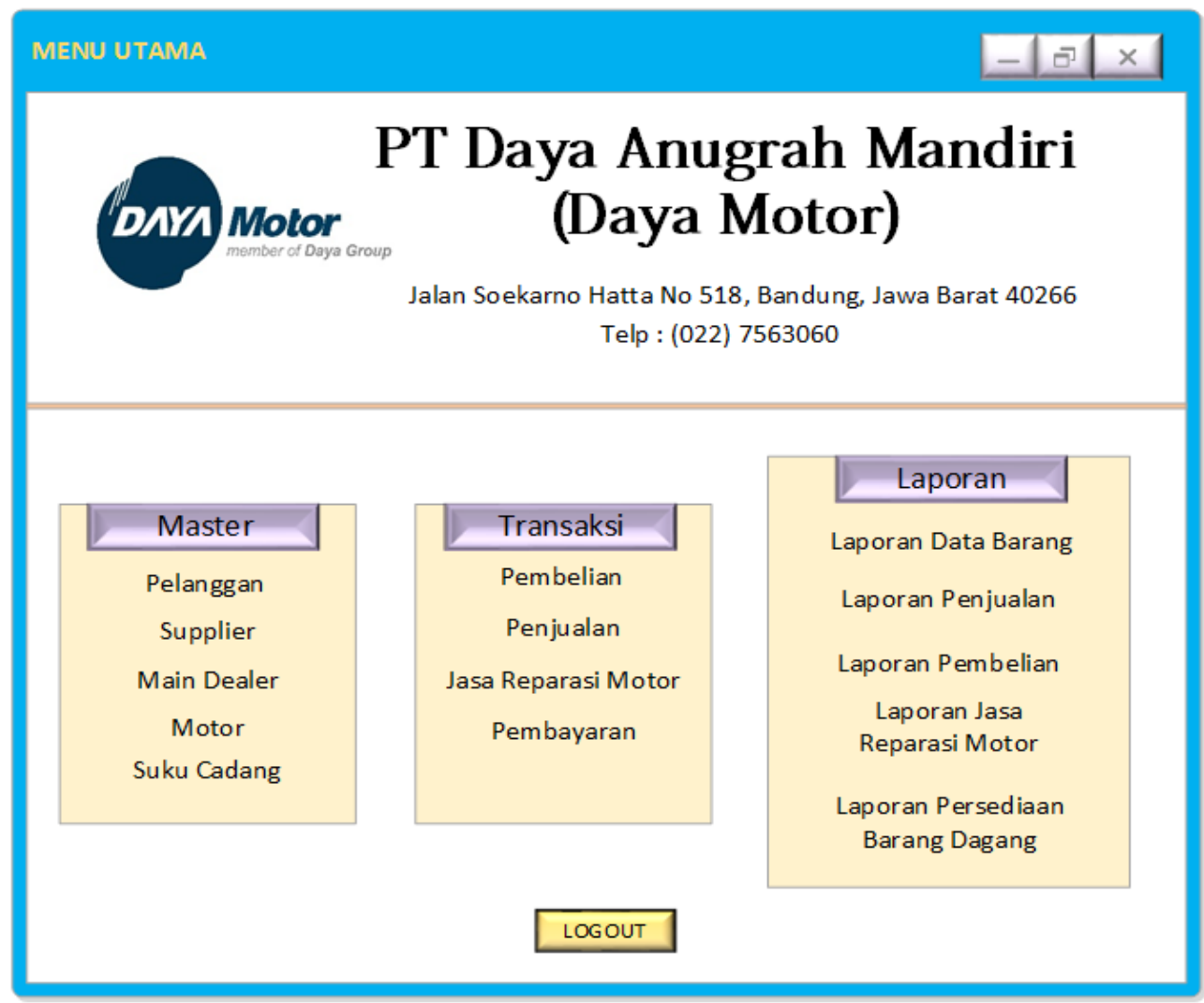

Gambar 5

Desain Main Menu Aplikasi

\section{PENGENDALIAN VALIDASI}

Pengendalian validasi digunakan untuk mencegah sistem dari kesalahan yang dilakukan pengguna pada saat penginputan data. Berikut adalah pengendalian validasi sistem penjualan, pembelian, jasa reparasi motor, dan persediaan barang dagang pada PT Daya Anugrah Mandiri.

Tabel 2

Pengendalian Validasi pada Transaksi Penjualan

\begin{tabular}{|l|l|l|}
\hline No & Judul Field & Pengendalian Validasi \\
\hline 1. & Kode penjualan & Field format check, completeness check, field length check \\
\hline 2. & Tanggal & Field format check, completeness check \\
\hline 3. & Nama barang & Completeness check \\
\hline 4. & Nama pelanggan & Field format check, completeness check. \\
\hline 5. & Alamat pelanggan & Field format check, completeness check. \\
\hline 6. & No telepon & Completeness check \\
\hline 7. & Kode barang & Field format check, completeness check, field length check \\
\hline 8. & Jenis barang & Completeness check, field format check \\
\hline 9. & Satuan, harga & - \\
\hline 10. & Jumlah & Completeness check, field format check \\
\hline 11. & Total harga & Completeness check, field format check, check digit \\
\hline
\end{tabular}


Sistem Informasi Akuntansi Penjualan, Pembelian, Jasa Reparasi Motor, dan Persediaan Barang Dagang pada PT Daya Anugrah Mandiri

Tabel 3

Pengendalian Validasi pada Transaksi Pembelian

\begin{tabular}{|l|l|l|}
\hline No & Judul Field & Pengendalian Validasi \\
\hline 1. & No pembelian & Field format check, completeness check, field length check \\
\hline 2. & Tanggal & Field format check, completeness check \\
\hline 3. & Nama barang & Completeness check \\
\hline 4. & $\begin{array}{l}\text { Nama supplier } \\
\text { atau main dealer }\end{array}$ & Field format check, completeness check. \\
\hline 5. & $\begin{array}{l}\text { Alamat supplier } \\
\text { atau main dealer }\end{array}$ & Field format check, completeness check. \\
\hline 6. & No telepon & Completeness check \\
\hline 7. & Kode barang & Field format check, completeness check, field length check \\
\hline 8. & Jenis barang & Completeness check, field format check \\
\hline 9. & Satuan, harga & - \\
\hline 10. & Jumlah & Completeness check, field format check \\
\hline 11. & Total harga & Completeness check, field format check, check digit \\
\hline
\end{tabular}

Tabel 4

Pengendalian Validasi pada Transaksi Jasa Reparasi Motor

\begin{tabular}{|l|l|l|}
\hline No & Judul Field & Pengendalian Validasi \\
\hline 1. & Kode service & Field format check, completeness check, field length check \\
\hline 2. & Tanggal & Field format check, completeness check \\
\hline 3. & No urut motor & Completeness check, field format chcek \\
\hline 4. & Nama pelanggan & Field format check, completeness check. \\
\hline 5. & $\begin{array}{l}\text { Alamat } \\
\text { pelanggan }\end{array}$ & Field format check, completeness check. \\
\hline 6. & Telepon & Completeness check \\
\hline 7. & No polisi & Completeness check, field format check, limit check \\
\hline 8. & No mesin & Completeness check, field format check, limit check \\
\hline 9. & No rangka & Completeness check, field format check, limit check \\
\hline 10. & Tipe & Completeness check \\
\hline 11. & KM & Completeness check \\
\hline 12. & Pekerjaan & Completeness check \\
\hline 13. & Estimasi biaya & Completeness check \\
\hline 14. & $\begin{array}{l}\text { Keluhan } \\
\text { pelanggan }\end{array}$ & Completeness check, field format check \\
\hline 15. & $\begin{array}{l}\text { Analisa service } \\
\text { advisor }\end{array}$ & Completeness check, field format check \\
\hline 16. & Suku cadang & Field format check \\
\hline 17. & Total harga & Completeness check, field format check, check digit \\
\hline
\end{tabular}




\section{KESIMPULAN}

Berdasarkan penelitian yang telah dilakukan, maka penulis menarik kesimpulan:

a. Dengan adanya sistem informasi yang dapat digunakan oleh setiap bagian, maka pencatatan transaksi keluar masuk barang sudah real time dan dapat terupdate sehingga tidak terjadi selisih pada hasil pencatatan.

b. Penulis mengusulkan untuk menambahkan bagian pembelian agar bagian gudang motor dan inventory part tidak merangkap pekerjaan sehingga bagian gudang dan inventory part dapat lebih fokus dengan pekerjaan nya.

c. Penulis mengusulkan agar pada gudang suku cadang dilengkapi alat pembatasan akses masuk ruangan yaitu card reader sehingga tidak bisa sembarang orang masuk ke gudang.

d. Informasi persediaan barang dagang masih terbatas karena belum real time sehingga penulis mengusulkan untuk proses pencatatan barang dagang secara real time.

e. Penulis merancang sistem baru terkomputerisasi untuk membantu dalam pembuatan laporan yang selama ini sering mangalami keterlambatan.

f. Penulis mengusulkan untuk memberikan batasan akses khusus untuk memasuki beberapa ruangan yang bersifat internal.

\section{DAFTAR PUSTAKA}

[1] A Hall, James. 2011. Sistem Informasi Akuntansi. Jakarta: Salemba Empat.

[2] B.Romney, Marshall, dan Paul John Steinbart. 2014. Sistem Informasi Akuntansi Edisi ke - 13. Jakarta: Salemba Empat.

[3] Jogiyanto. 2009. Sistem Informasi Manajemen. Yogyakarta : Penerbit Andi.

[4] Krismiaji. 2010. Sistem Informasi Akuntansi edisi ketiga. Yogyakarta: Unit Penerbit dan Percetakan Sekolah Tinggi Ilmu YKPN.

[5] Mulyanto, Agus. 2009. Sistem Informasi Konsep dan Aplikasi. Yogyakarta: Pustaka Pelajar.

[6] Puspitawati, Lilis dan Sri Dewi Anggadini. 2011. Sistem Informasi Akuntansi. Yogyakarta: Graha Ilmu.

[7] Rudy Tantra 2012. Manajemen Proyek Sistem Informasi. Yogyakarta : Andi

[8] Sarosa, Samiaji. 2009. Sistem Informasi Akuntansi. Jakarta: Gramedia Widiasarana Indonesia.

[9] Sujarweni, V. Wiratna. 2015. Statistik untuk Bisnis dan Ekonomi. Yogyakarta: Pustaka Baru Press.

[10] Susanto, Azhar. 2013. Sistem Informasi Akuntansi. Bandung: Lingga Jaya.

[11] Sutabri, Tata. 2012. Analisis Sistem Informasi. Yogyakarta: Andi.

[12] Sutabri, Tata. 2012. Konsep Sistem Informasi. Yogyakarta: Andi.

[13] Sutanta, Edhy. 2011. Basis Data dalam Tinjauan Konseptual. Yogyakarta: Penerbit Andy. 